\title{
Participations to European Framework Programs of higher education institutions and their association with organizational characteristics
}

\author{
Benedetto Lepori ${ }^{1}$ - Valerio Veglio ${ }^{1}$ Barbara Heller-Schuh ${ }^{2}$. \\ Thomas Scherngell ${ }^{2} \cdot$ Michael Barber $^{2}$
}

Received: 21 May 2015/Published online: 12 October 2015

(C) Akadémiai Kiadó, Budapest, Hungary 2015

\begin{abstract}
This paper aims to analyze patterns of participation of higher education institutions (HEIs) to European Framework Programs (EU-FP) and their association with HEI characteristics, country and geographical effects. We have analyzed a sample of 2235 HEIs in 30 countries in Europe, derived from the European Tertiary Education Register (ETER), which has been matched with data on participations in EU-FPs in 2011 using the EUPRO database. Our findings identified (1) a high concentration of EU-FP participation in a small group of HEIs with high reputation; (2) the participation of non-doctorate awarding HEIs in EU-FPs is very limited despite the fact that they account for a significant share of tertiary student enrolments; (3) the number of participations tends to increase proportionally to organizational size, and is strongly influenced by international reputation; (5) there is limited evidence of significant country effects in EU-FP participations, as well as of the impact of distance from Brussels. We interpret these results as an outcome of the close association between HEI reputation and the network structure of EU-FP participants.
\end{abstract}

Keywords Higher education institutions - Reputation · Core-periphery networks $\cdot$ EU Framework programs

\section{Introduction}

The importance of European Framework Programs (EU-FPs) has dramatically increased since the first EU-FP was launched in 1984 (Guzzetti 1995). EU-FPs are now one of the main instruments of European research policy (Edler et al. 2003). While on the aggregate

Benedetto Lepori

blepori@usi.ch; benedetto.lepori@usi.ch

1 Centre for Organisational Research (CORe), Universitá della Svizzera Italiana, Via Lambertenghi, 10, 6900 Lugano, Switzerland

2 AIT Austrian Institute of Technology GmbH, Donau-City-Strasse 1, 1220 Vienna, Austria 
they accounted for only about $7 \%$ of public research funding in the European Union in 2010 (European Commission 2011), for highly reputed universities, they comprise a central funding source for internationally-oriented research (Geuna 1998b). With the establishment of the European Research Council (ERC) in 2007, EU-FPs also became a central source of highly reputed grants for basic research, competing with national research councils (Nedeva 2012). Supporting excellence and achieving integration in the European Research Area (ERA) has therefore become the two central goals of EU-FPs since the launch of the ERA strategy in 2000.

Previous studies have mainly focused on the policy design rationale of FP programs, as associated with the development of a strategy for the European Research Area (Banchoff 2002; Kuhlmann 2001), as well as on the evaluation of the impact of EU-funded R\&D cooperative projects (Arnold 2012). These analyses mostly investigated the industrial implications of EU-funded projects (Malerba 2006; Ormala and Vonortas 2005) and structural effects like the creation of a stable research cooperation (Heller-Schuh et al. 2011) and the structuring of research domains at the European level (Luukkonen and Nedeva 2010).

Studies on factors accounting to participation mostly focused on the collaborative structure of EU-FP networks as the main determinant of participation (Autant-Bernard et al. 2007; Heller-Schuh et al. 2011). They identified the presence of a stable backbone of organizations, which are highly central in the collaboration network and account for most of the participations (Breschi and Cusmano 2004).

When dealing with Higher Education Institutions, which constitute in many countries the core of the public research system and accounted for $1 / 3$ of total participations in EUFP6 (European Commission 2011), there is evidence that participations are strongly concentrated in the most reputed universities (Heller-Schuh et al. 2011; Nokkala et al. 2011; Annerberg et al. 2010) and that organizational characteristics, particularly size and reputation, influence the number of participations (Geuna 1996 and Geuna 1998b).

The importance of network ties and structure for EU-FP participation is not incompatible with the number of participations depending on individual organizations' characteristics. Many social networks are characterized by a strong layering where the most reputed organizations are more central and connected and where the number of ties can be quite precisely predicted by the individual organization reputation (Borgatti and Everett 1999).

Therefore, the main goal of the paper is to test empirically to which extent the participation of Higher Education Institutions to EU-FPs can be predicted from their individual characteristics. We do not only focus on the presence of organizational effects, known from the previous literature, but also on the extent differences in number of participations are explained by them.

We use a sample of 2235 HEIs in 30 European countries derived from the ETER database, which has been matched with data on participations to EU-FP for the year 2011 from the EUPRO database (Roediger-Schluga and Barber 2008a). We also provide a preliminary test of the stability of patterns of participation between the years 2008 and 2011. We are particularly interested in finding evidence of scaling effects in participations with size, as these would have relevant policy implications for concentration policies in public research. Besides size and reputation, we test the impact of a broader set of variables on research orientation, teaching orientation, subject specialization and the availability of external funding.

Since our sample covers almost all HEIs in the considered countries, we also provide evidence on the distribution of participations across the entire higher education system, 
beyond the focus of previous studies on universities. We particularly focus on whether participation to EU-FP has extended to Universities of Applied Science (UAS). In many European countries, UAS have become a major actor in higher education, accounting for a large share of student enrolments while also developing applied research activities, which would have a good fit with some areas of FPs (Lepori and Kyvik 2010).

We finally analyze geographical differences in the level of HEI-participations, and particularly, the presence of country effects. Empirical evidence from the $90 \mathrm{~s}$ showed that country effects were indeed large (Geuna 1998b), but it is generally believed that spatial effects have become less important for EU-FP participations since 2000 as an outcome of the European Research Area becoming more integrated (Scherngell and Lata 2013), but limited empirical evidence has been provided so far.

An understanding of the factors associated with EU-FP participation is relevant from several perspectives. At the European level, it is indicative of the reach of European funding policies in terms of groups of HEIs and of countries, as well as of the balance between supporting excellence and cohesion in the European Research Area. For national research policies, it provides important information on how the rate of HEI-participation is influenced by the distribution of resources and the level of concentration of research activities within the country. Finally, in broader terms, our work also contributes to the literature on cumulative effects in the allocation of funds to public research organizations, and particularly, on the presence of scaling effects with organizational size and the importance of reputation.

The paper is organized as follows. In Theoretical framework section, we review the literature on EU-FP participations and we develop our hypotheses, while in Methodology section, we present data, variables and methods. In Results section we present our results, while the paper is concluded with a discussion of findings, policy implications and directions for further research

\section{Theoretical framework}

\section{EU Framework Programs as collaborative undertakings}

Most of the literature has focused on network collaboration as the main factor determining patterns of participation to EU-FPs -(Breschi and Cusmano 2004; Autant-Bernard et al. 2007; Heller-Schuh et al. 2011). To a large extent, this was due to the nature of these programs, but it was also contingent to the better availability of data on participations than on the characteristics of organizations.

A major characteristic of EU-FPs is their collaborative nature, where, for most subprograms, individual partners join consortia and their chances of success are not due only to individual quality, but also to the quality of their network. Framework programs are therefore networking environments aiming at establishing cooperation between research partners (Caloghirou et al. 2002; Breschi et al. 2009).

Most empirical studies of EU-FP adopted a social network perspective, investigating structural properties of the collaborative network (Roediger-Schluga and Barber 2008a). They consistently display a skewed distribution with a giant component or backbone composed by a number of organizations with high network centrality (Breschi and Cusmano 2004; Heller-Schuh et al. 2011). The network structure displays a high level of stability, with the same organizations occupying central places over time (Paier and 
Scherngell 2011). Other studies focused on the dynamics of cooperation between universities and industry, showing its increase over time and the tendency of universities to participate to larger and more long-term projects (Caloghirou et al. 2001; Scherngell and Barber 2011).

In a social network perspective, three types of mechanisms can be identified leading to the establishment of network ties, i.e. the characteristics of individual nodes, structural effects associated with preferential attachment and spatial effects associated with distance and the presence of borders (Rivera et al. 2010).

In the case of universities, studies consistently show that participations are concentrated in the most reputed international universities (Heller-Schuh et al. 2011; Nokkala et al. 2011; Annerberg et al. 2010), which participate more in areas close to the knowledge frontier, such as life sciences, nanotechnology and information society (Heller-Schuh et al. 2011). However, descriptive evidence cannot disentangle whether this is due to their larger size or reputation.

Following the literature on cumulative advantage (Viner et al. 2004), Geuna suggested that the participation process is driven by a reputational principle associated with various types of cumulative mechanisms (Geuna 1996, 1998b). The analysis showed that the distribution of participations is extremely skewed, with very few universities achieving a high number of participations. Both the number of times that an institution has participated in EU-FPs and the HEI's probability of joining an EU-FP are influenced by their level of scientific research productivity. This analysis found also significant disciplinary effects, with universities specialized in technical domains having more participations. Two major limitations of this study are, first, that it pre-dates the establishment of the ERA strategy and the enlargement of the European Union; second, the sample is somewhat limited as it covers less than 400 doctorate-awarding universities in 12 European countries.

Social Network analysis demonstrated that powerful processes generate ties between organizations from other ties, leading therefore to a self-organization of the network. Two important mechanisms in this respect are preferential attachment-i.e. that new ties are preferentially generated from pre-existing ones (Barabasi and Albert 1999)—and, social closure, i.e. that the likelihood of a tie between two organizations which are both linked to the same other organizations is higher (Burt 2005). Preferential attachment leads to a concentration of links and to the typical scale-free distribution of network characteristics, while social closure to the creation of cliques. Both characteristics are well-known for EUFP collaboration networks (Autant-Bernard et al. 2007; Barber et al. 2006), but disentangling empirically network effects from effects of antecedents is complex because of endogeneity.

Finally, the extent of scientific collaboration tends to decrease with distance and with national borders (Frenken et al. 2009; Hoekman et al. 2010), even if a decreasing importance of space and increasing international collaboration has been demonstrated, particularly in the case of scientific collaboration (Chessa et al. 2013).

Similar evidence has been provided for EU-FPs participations and collaborations. Analyses of spatial collaboration patterns demonstrate that geographical, institutional, cultural and technological barriers influence the probability of cross-region FP5 collaboration activities (Scherngell and Barber 2011). These studies display a concentration of participations and collaborations in the most central European regions; when accounting for the extent of participations, collaboration indeed decreases with distance and national borders, but the strength of the effect strongly decreased after 2000 (Scherngell and Lata 2013). 


\section{Determinants of participation}

The fact that EU-FP participations are generated from social ties and network structure is not incompatible with their aggregate number being associated with the characteristics of the individual organization, since the network structure is not independent from organizational characteristics. The previous review allows identifying different mechanisms and, therefore, hypotheses on the determinants of participations.

First, the number of participations is expected to increase with the research capacity of the organization, as organizations with more research capacity have more research teams (and, possibly, cover different topics) and therefore engage in more collaborations, as demonstrated in the case of companies (Veugelers and Cassiman 2005; Barajas and Huergo 2010).

Since HEIs are multifunctional organizations and the share of research in their activities varies strongly (Daraio et al. 2011), research capacity can be conveniently operationalized through organizational size, as measured by the number of academic staff, and a measure of research intensity. Lacking of a good measure of the volume of $\mathrm{R} \& \mathrm{D}$ expenditures, research intensity is usually computed as the number of doctoral graduates over undergraduate degrees (Bonaccorsi et al. 2007). In more research oriented HEIs, the share of staff involved in research will be higher and individual staff will be more engaged in research and, therefore, be more likely to participate to EU-FPs.

Complementarily, we consider the so-called teaching load, defined as the number of undergraduate students over academic staff (teaching load). In HEIs with higher teaching load, staff will devote more time to education and, therefore, be less available to engage in research collaborations.

The baseline expectation is that the number of participations is roughly proportional to size. Scaling effects, i.e. participations growing more rapidly than size, could occur, for example because larger HEIs offer better common infrastructures, more developed support services and more opportunities for internal cooperation. However, the rationale for scaling effects of size at the organizational level is weak and the empirical evidence is contradictory, except in the case of very small research teams (Brinkman and Leslie 1986; Bonaccorsi et al. 2006).

Secondly, the number of participations is expected to increase with the HEI reputation. At the individual level, the acquisition of research funds is strongly influenced by the researcher's reputation, which matters more than proposal quality in the selection process (Viner et al. 2006; Laudel 2006a; Van den Besselaar and Leydesdorff 2009). For collaborative research, a central function of reputation is to drive the establishment of research collaborations: higher-reputed researchers and organizations will be sought to a greater extent as research partners (Evans et al. 2011) and, therefore, move to the center of the network, as demonstrated by studies of EU-FPs networks (Breschi and Cusmano 2004; Heller-Schuh et al. 2011).

This central position will in turn generate additional collaborations and participations through preferential attachment. In other words, reputational hierarchy and network structure coevolve and reinforce mutually, leading to the stable long-term layering observed in many social networks (Owen-Smith and Powell 2008), including exchange of PhD graduates (Burris 2004), weblinks (Lepori et al. 2013) and EU-FPs (Paier and Scherngell 2011). This implies that much of the network structure is expected to be accounted for by the organizational reputation. 
We additionally test for the impact of the composition by subject domains and the availability of other funding sources.

EU-FP funding is concentrated on technological domains which are critical for the economic development of Europe, whereas funds for social sciences and, especially, humanities are more limited (European Commission 2011). Since scientists are usually very specialized, the match between their topic and EU-FP's funding priorities will largely determine their opportunity to receive funding. European HEIs display different subject compositions and many, mostly either in technology or towards humanities, are highly specialized (Lepori et al. 2010). We therefore expect that a stronger orientation towards fields like ICT and engineering are associated with a higher number of participations, whereas an orientation towards social sciences and humanities will have a lower number (Geuna 1998b).

The impact of the availability of other funding sources is potentially ambiguous. On the one hand, a high level of resourcing is expected to positively influence participation, since scientists will have more resources to prepare proposals and can fund preparatory research by other means (Laudel 2006b). On the other hand, crowding out might occur, i.e. receiving other funds (for example from national funding agencies) may discourage an organization from applying for European funds, because of different research orientations, heightened bureaucracy, or simply, for capacity reasons (Connolly 1997).

Crowding out is a well-known issue for industrial participation to EU-FPs and their innovation impact (David et al. 2000; Luukkonen 2000), but has been rarely investigated in the case of HEIs. This issue is relevant for European policies since EU-FPs only account for a small share of total public research funding in EU countries (European Commission 2011): crowding out would imply that EU-FPs are a second choice resource for teams which are not well funded by national sources. On the contrary, a strong association with of national funds would imply that FPs largely follow national allocation decisions and would therefore question their ability to promote European excellence.

We finally test for the presence of country effects. All studies display large differences in the number of participations by European countries, with Germany and the UK having a much larger number of participations, followed by the other large Western European countries (FR, IT, ES) and by small research-intensive countries like Belgium, Netherland, Finland, Sweden, Norway and Switzerland. Central and Eastern European countries have much lower numbers of participations, especially when compared to country size (European Commission 2011).

We expect that most of these differences are due to systematic variations in the characteristics of HEIs by country, particularly in terms of international reputation. We test whether, once controlled for HEI characteristics, there is evidence of some countries participating more to EU-FPs. Indeed, in the 90s, Geuna found clear evidence that countries farther away from Europe's core are less involved in EU-FPs. Based on these results, he speculated that the cohesion policy is an advantage for Irish and Greek universities, whereas Belgian universities profited from easier access to information and contact with the European Commission (Geuna 1998a).

Other potential mechanisms leading to country effects are systematically different perceptions of quality by potential partners depending on the level of development of their country, as well as political priorities in EU-FPs-i.e. the fact that projects including partners from Mediterranean or New Members States are favored in order to order to promote cohesion. Associated Countries, like Switzerland and Norway, contribute directly to EU-FPs from their research budget and therefore might be proactive in pushing HEIs 
participation. It is however uncertain whether these mechanisms are still relevant almost two decades after the launch of the ERA strategy.

\section{Methodology}

\section{Sample and data sources}

The analysis in is based on the European Tertiary Education Register (ETER) database. It is composed of 2235 HEIs in 30 countries (EU-28 excluding the French part of Belgium, Hungary, Romania and Slovenia, plus Iceland, Liechtenstein, Norway, Former Yugoslav Republic of Macedonia and Switzerland) for the years 2011 and 2012. ETER provides an almost complete coverage of institutions graduating at least at the bachelor level in the considered countries and therefore our sample by large represents the total population of HEIs that could participate in EU-FPs.

The ETER database contains information on the number of academic staff, numbers of students and graduates, subject mix and funding. The largest number of observations is in Germany (387), followed by France (286) and Poland (273). We hold similar information for the year 2008 from the EUMIDA project (Bonaccorsi 2014), but on a smaller samplethe number of matched cases being 1225. These data will be used for a more limited investigation of changes over time.

The ETER list of HEIs was matched with the number of participations in EU-FPs collected in the EUPRO database from 2008 to 2013 (Roediger-Schluga and Barber 2008b). The latter includes information on more than 60,000 research projects funded by EU-FPs and all participating organizations. In particular, the EUPRO database contains information on the participants' organization (full name, full address, type of organization and the name of the EU-FP project in which the organization is involved). We have identified 861 HEIs with at least one EU-FP participation in 2011; all remaining HEIs in the ETER list have been attributed the value 0 . There is the possibility that some ETER HEIs which participated to EU-FPs were not correctly identified in EUPRO, but we consider that this phenomenon to be marginal.

\section{Variables}

Our dependent variable is the count of HEI's participations in EU-FPs in the year 2011 derived from the EUPRO database. Multiple participations by the same university have been considered, if different entities (institutes, departments) take part in the same project and are indicated as a distinct partner in the Community Research and Development Information Service (CORDIS; cordis.europa.eu), which provides information on all EU-funded projects. We counted all participations in projects that were ongoing in the year 2011.

Counts for the years 2012 and 2013 are correlated to $0.99 * * *$ to those for 2011, thus displaying the stability of our dependent variable.

\section{HEI-level variables}

Size is the number of academic staff (Full Time Equivalents measured in thousands). It includes employees who are mostly involved in education and research, excluding technical and administrative personnel. 
Reputation is measured as the product between normalized impact factor and the total number of publications from the concerned HEIs (Van Raan 2008), normalized by the number of academic staff. This variable combines the volume and quality of publications in a single measure of visibility. The data were derived from the SCIMAGO institutional ranking for the year 2011 (http://www.scimagoir.com/), which is based on data from the period 2007-2011. We have data for 614 HEIs in the dataset-the other HEIs are not covered since they had less than 500 publications in Scopus during the reference period. Given the low level of the inclusion threshold, reputation for all other HEIs has been set to "0". The score for 2008 is computed from data for 2004-2008.

PhD Awarding is a dummy variable with a value 1 when the HEI has a legal right to award a doctorate and 0 otherwise; the right to award a doctorate is one the main distinctions between universities and universities of applied sciences (Lepori and Kyvik 2010).

Research Intensity is the ratio between the share of $\mathrm{PhD}$ graduates and the number of undergraduate graduates, which is a commonly used indicator when determining the research orientation of an HEI (Bonaccorsi et al. 2007). Numbers of graduates are preferred to students as they are more reliable at the PhD level.

Teaching load is a measure of the HEI's orientation towards education, which is expected to be negatively associated with participations in EU-FPs. It is computed as the ratio between the total number of undergraduate students and academic staff.

External Funding is the share of third-party funds in total HEI revenues. Third-party funds are composed of grants from public funding agencies (for example research councils), contracts from the public sector and from private companies, and are mostly oriented towards research. This variable is partially endogenous as European funds are included (but for most HEIs these constitute a small portion of total third-party funds).

We use two types of variables for subject specialization. First, a set of dummies for specialized HEIs identify those HEIs as having more than half of their undergraduate students in a field. We adopt the standard classification of Fields of Education adopted in international educational statistics, i.e.: education; humanities and arts; social sciences; business and law; natural science, mathematics and statistics; information and communication technologies, engineering, manufacturing and construction; agriculture, forestry, fisheries and veterinary; health and welfare; services (UOE 2013).

Second, for analyzing the number of participations, we use the share of undergraduate students in natural and technical sciences (including ICT).

Geographical Distance measures the distance between the HEI's headquarters (as identified by their geographical coordinates in ETER) and Brussels (great circle distance). We use the log of the kilometer distance as an independent variable.

\section{Country-level variables}

Higher Education Research and Development Expenditures (HERD) per Inhabitant in purchasing power parities is a measure of the national research investment in higher education, normalized by the size of the country and corrected by national price differences for the year 2011 (http://www.eurostat.com/2. We do not include a measure of national wealth (GDP per inhabitant) as this is highly correlated with the former variable.

New Member State is a dummy variable identifying those countries that accessed the EU after 2000, mostly in Central and Eastern Europe (Czech Republic, Estonia, Hungary, Latvia, Lithuania, Poland, Slovakia, Slovenia, Cyprus and Malta). 
Associated country is a dummy variable identifying non-EU countries, which in 2011 were associated to EU-FPs, in our case Switzerland, Norway, Iceland, Liechtenstein, Croatia, and the Former Yugoslav Republic of Macedonia.

\section{Methods}

The choice of the regression method needs to take into account that our dependent variable is a count, is highly skewed and is null for more than half of the sample. An approach would be to use a negative binomial regression with a hurdle model, which specifies a logistic regression model in order to predict whether the case is null and passes the case to a negative binomial model to predict non-zero counts (Cameron and Trivedi 1998).

However, in the case at hand, once the null values are excluded, the data are not extremely skewed. Therefore, we prefer running two distinct models following the approach adopted by Geuna 1998a: the first model is a binary logistic regression run on a dichotomized dependent variable (no projects $=0$; at least one project $=1$ ) and thus predicts whether an HEI participates in EU-FPs.

The second model computes the predicted number of participations through a truncated linear regression applied to the non-zero cases; we perform a log transformation of the dependent variable as well as of the number of academic staff in order to reduce its skewedness. Truncated regression models take into account in the estimators the fact that values below some threshold ( 0 in our case) have been removed from the sample (Long 1997). The log-transform of our dependent variable is nearly normal, and therefore, the use of this approach is adequate.

In our empirical setting, individual HEIs are nested within countries, and therefore, we cluster standard errors in order to control for correlations between HEIs within the same country. We ran models using only HEI variables and models also including the country variables in order to analyze their relative contribution to HEI participation in FP programs. We also tested an alternative specification of all models as random intercept multilevel models (equivalent to random effect panel models). This specification is more robust against correlations within countries, which are explicitly taken into account in the estimates (Snijders and Bosker 2004). Results are very similar to the single-level regression.

We notice that the effective sample for the regressions is smaller since data on the HEIdependent variables are missing in the ETER database for some HEIs and countries. This is particularly the case for models including the third-party funding variable. We also exclude from all models four cases because of their specific characteristics (graduate schools with no undergraduate students).

We use different measures of fit for the models, including loglikelihood and the Akaike Information Criterion (AIC). The latter takes into account both the statistical goodness of fit and the number of parameters that have to be estimated to achieve this particular degree of fit, by imposing a penalty for increasing the number of parameters. Lower values of the index indicate the preferred model. In addition, for the logistics regression, we also measure fit as the percentage of correctly classified cases, while for the truncated regression we compute a pseudo Rsquare as the amount of variance explained by the regression for the considered population.

In order to test for the stability over time of the observed participation patterns, besides a cross-sectional model for the year 2011, we perform a test on changes in participation numbers between 2008 and 2012 (the extreme years for which we hold data). The model is specified as follows: 


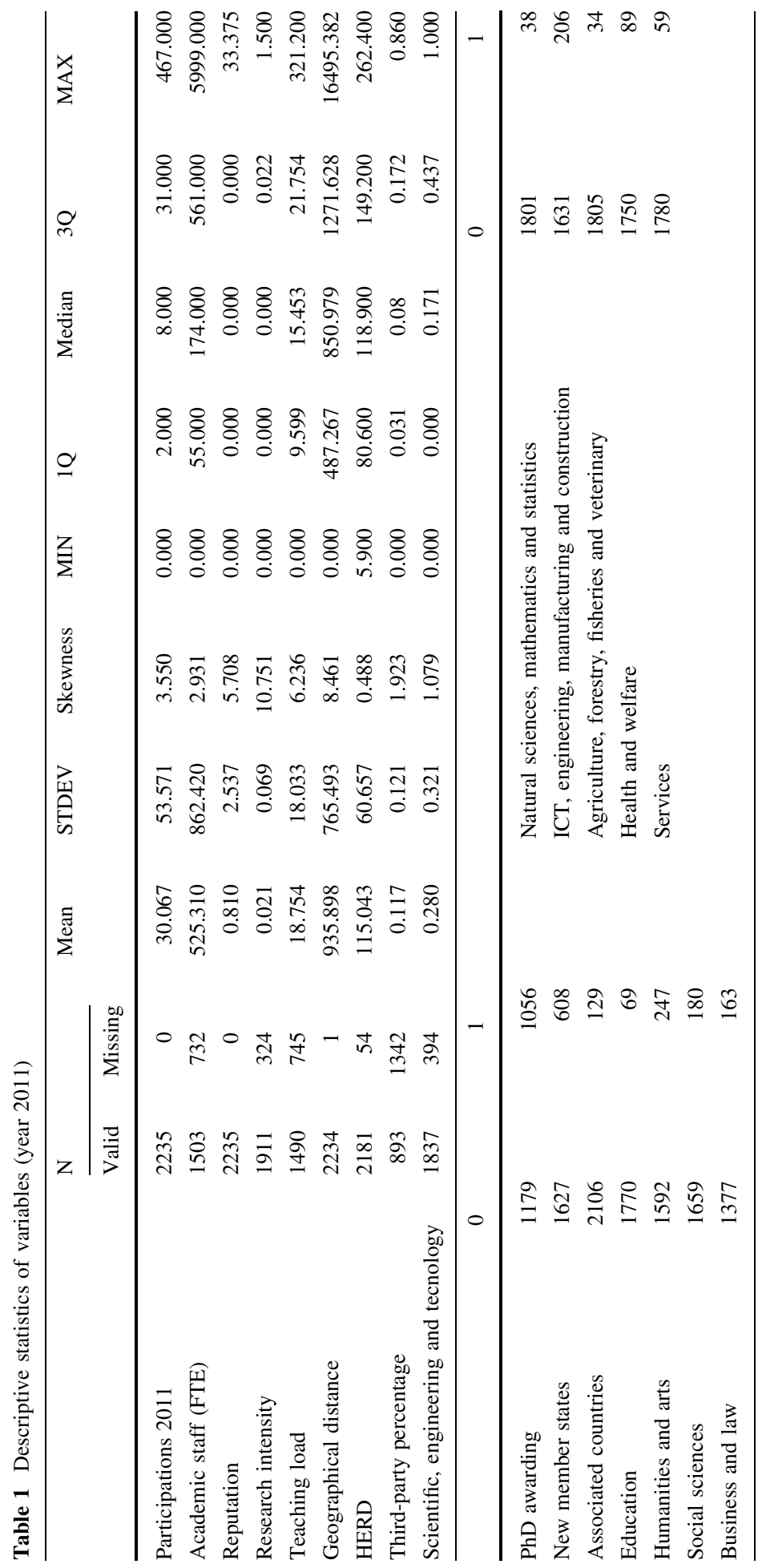




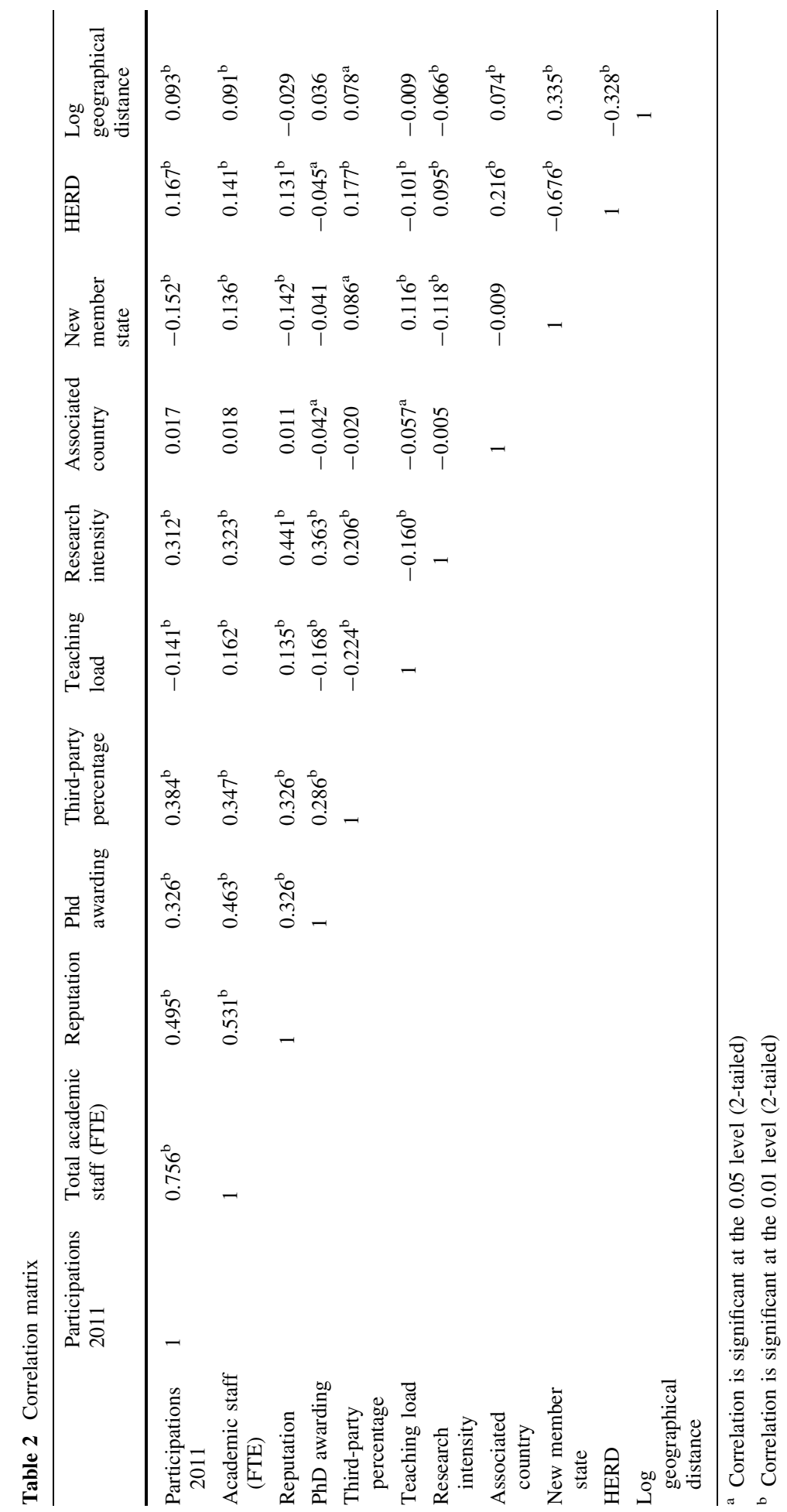




$$
\begin{aligned}
\ln \left(\text { participations }_{2012}\right)= & \alpha+b * \ln \left(\text { participations }_{2008}\right)+\gamma * \ln \left(\operatorname{staff}_{2008}\right)+\delta \\
& * \ln \left(\text { reputation }_{2008}\right)
\end{aligned}
$$

In other words, we assume that on-going projects in 2008 generate projects in 2012, while new projects are acquired as dependent from organizational size and reputation in the former year. As for the cross-sectional, the model is estimated as truncated regression with clustered standard errors at the country level. We test only a reduced model including size and reputation, as otherwise the number of cases would be too low.

\section{Results}

\section{Descriptive analysis}

Table 1 provides descriptive information concerning the variables considered in the empirical analysis.

Most HEI-level variables are highly skewed, the distribution of academic staff is nearly lognormal, as would be foreseen by Gibrat's law (Ijiri and Simon 1964), whereas reputation, research intensity and teaching load are even more skewed and have a large number of nulls (mostly non-PhD awarding HEIs).

The dummy variables provide additional information on the composition of the sample. More than half of the sample is composed of HEIs that do not award a $\mathrm{PhD}$, thus showing how our sample extends well beyond doctorate-awarding universities. The dummy variables for subject specialization identifies groups of specialized HEIs in individual fields, which includes half of our sample. Most specialized HEIs are in arts and humanities (247), social sciences (180), business and law (163), and ICT, engineering, manufacturing and construction (206).

Table 2 displays significant positive correlations between the number of participations and most HEI variables, particularly size and reputation. Expectedly, the correlation with teaching load is negative. There are also significant positive correlations with national investment (GDP and HERD) and negative correlations with the New Member States dummy. The correlation with distance from Brussels is significant and negative.

A few correlations between independent variables are significant. The correlation between academic staff and reputation is fairly large $\left(0.531^{* *}\right)$, despite the fact that the latter is normalized by size, owing to the scaling effects of scientific reputation (Van Raan 2008). Correlations with research intensity are fairly high $\left(0.323^{* *}\right.$ for size and $.441^{* *}$ for reputation), while the variable "PhD Awarding" is strongly correlated with size $\left(0.463^{* *}\right)$, research intensity $\left(0.363^{* *}\right)$ and reputation $\left(0.326^{* *}\right)$. Expectedly, New Member States have lower levels of HERD, whereas Associated Countries have higher levels.

\section{Patterns of participations}

As expected, the distribution of HEI participations in EU-FPs is highly skewed. Approximately $61 \%$ of the HEIs have no participations, while only $18 \%$ have more than 10 participations and only $8 \%$ of HEIs have more than 100 participations (70 out of 2235 HEIs in our population).

The concentration of participations is rather high: the maximum count of participations is 467 projects, while the 157 HEIs with more than 50 participations account for $72 \%$ of 
the total participations. This group of HEIs enrolls only one-quarter of the undergraduate students and half of the PhD students in the whole sample and it accounts for about $38 \%$ of the total staff and $58 \%$ of the number of scientific publications. Therefore, participations in EU-FPs are even more concentrated than $\mathrm{PhD}$ students and scientific publications.

As Table 3 shows, $72 \%$ of the doctorate-awarding HEIs participated in an FP in 2011, whereas this share was only $20 \%$ for non-doctorate awarding HEIs. In fact, non-doctorateawarding HEIs account for only $6 \%$ of the participations, while constituting $53 \%$ of our sample. Just a handful of Universities of Applied Sciences, mostly Swiss and German Fachhochschulen, had more than 5 participations. Strong differences also emerge for specialized HEIs when compared to generalist ones: as it would be expected, HEIs specialized in education, humanities and arts, as well as to a lower extent social sciences and business are less likely to participate, while those specialized in ICT and engineering participate to a larger extent.

There are large differences between countries in their total number of participations and in participations per HEIs. The UK has the largest number of participations (6009 participations), followed by Germany (3582 participations), while the average number of participations per HEI varies between 26.4 for Denmark and 2.1 for Macedonia. However, Fig. 1 shows that differences between HEIs within the same countries tend to be larger than differences between countries; as a matter of fact, $90 \%$ of the variance in the number of participations is within countries and only $10 \%$ between countries (ANOVA test).

Individual data points are the number of HEI participations. The lower level of the boxes is set to $1 \mathrm{Q}$, the higher to $3 \mathrm{Q}$, the line in-between represents the median of each country distribution; the bars correspond to 5-95\% of the distribution. Individual points represent outliers.

Longitudinal data confirm the stability of the relative numbers of participations over the period 2008-2012, the raw correlations between the number of EU-FPs in the two years being $0.968 * *(N=1225)$, despite the fact that the total number of EU-FP participations in the considered period for these HEIs increased by $14 \%$.

The same pattern is confirmed by comparing then number of participations by strata and by rank ordering of HEIs by their number of participations. $85 \%$ of the HEIs belonged to the same group in 2008 and 2012, while most of the moves are between 0 and 1participations, which are less significant (Table 4). In terms of ranks, among the ten HEIs with

Table 3 Participation of EU-FP, year 2011 by groups (PhD awarding, subject specialization)

\begin{tabular}{llcc}
\hline & $\%$ Participating HEIs & \multirow{2}{*}{ Sig. (2-sided) } \\
\cline { 2 - 3 } & $0 \%$ & $1 \%$ & 0.001 \\
\hline PhD awarding & 20 & 72 & 0.000 \\
Education & 39 & 6 & 0.000 \\
Humanities and arts & 43 & 4 & 0.000 \\
Social sciences & 40 & 17 & 0.000 \\
Business and law & 41 & 15 & 0.570 \\
Natural sciences, mathematics and statistics & 38 & 42 & 0.000 \\
ICT, engineering, manufacturing and construction & 36 & 50 & 0.086 \\
Agriculture, forestry, fisheries and veterinary & 38 & 24 & 0.000 \\
Health and welfare & 39 & 17 & 0.000 \\
Services & 39 & 7 & \\
\hline
\end{tabular}

Chi square test for significance of differences 


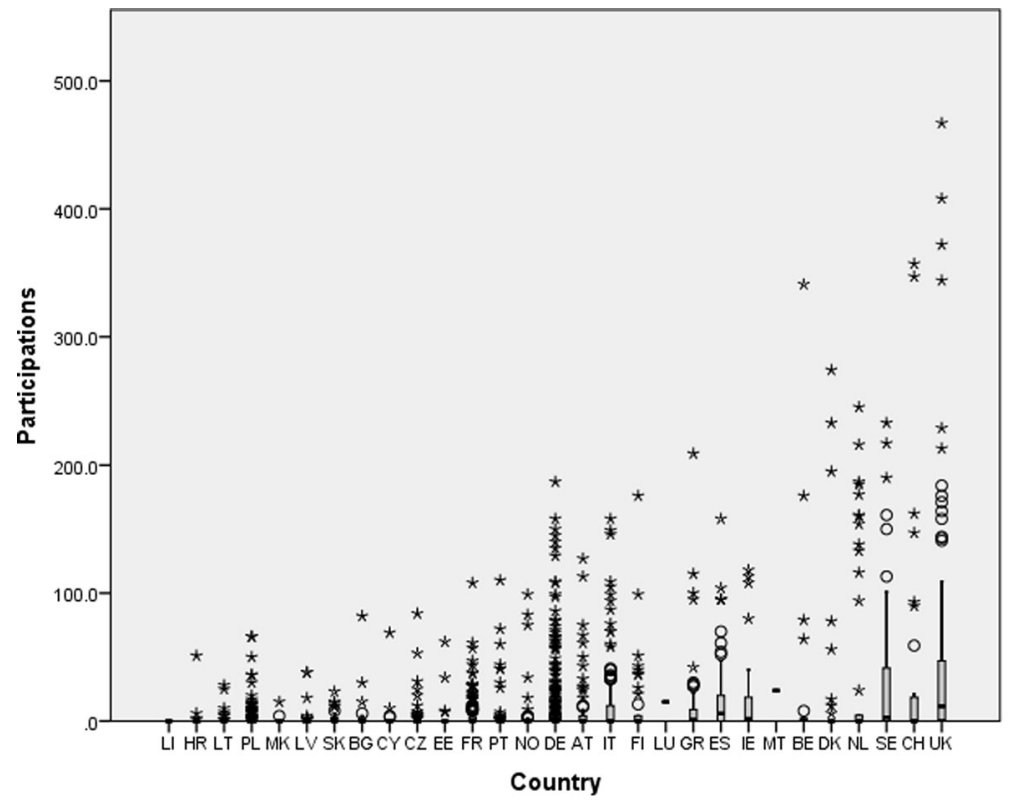

Fig. 1 Boxplot of HEIs participations to EU-FP by countries

higher number of participations in 2008, seven were still in the top-ten in 2012 and among the top-50 participating HEIs in 2008, 44 were still in the top-50 in 2012.

\section{Probability of participating}

Table 5 presents the results of a logistics regression to predict whether an HEI had at least one participation in an EU-FP during 2011. We ran country models without the share of third-party funds, because this variable is not available for most new member states.

The introduction of HEI size strongly improves the fit of the model and its ability to identify HEIs participating in EU-FPs. The addition of other HEI variables further improves the model: the HEI model is able to correctly classify more than $88 \%$ of the HEIs, which is quite a good performance when considering that our cases are divided almost equally between participating and non-participating. The introduction of country dummies only slightly improves the fit, showing that while some country effects might still be present, their impact on participations is limited (as compared to HEI characteristics).

Table 4 Participations in 2008 versus 2012 by groups

\begin{tabular}{llrrrrr}
\hline & & 2012 & & & & \\
\cline { 3 - 6 } & & 0 & 1 & $2-10$ & $11-100$ & $100-$ \\
\hline 2008 & 0 & 458 & 67 & 37 & 3 & 0 \\
& 1 & 41 & 20 & 22 & 0 & 0 \\
& $2-10$ & 26 & 28 & 127 & 28 & 0 \\
$11-100$ & 0 & 0 & 24 & 263 & 15 \\
$100-$ & 0 & 0 & 0 & 5 & 61 \\
\hline
\end{tabular}

$N=1225$ 


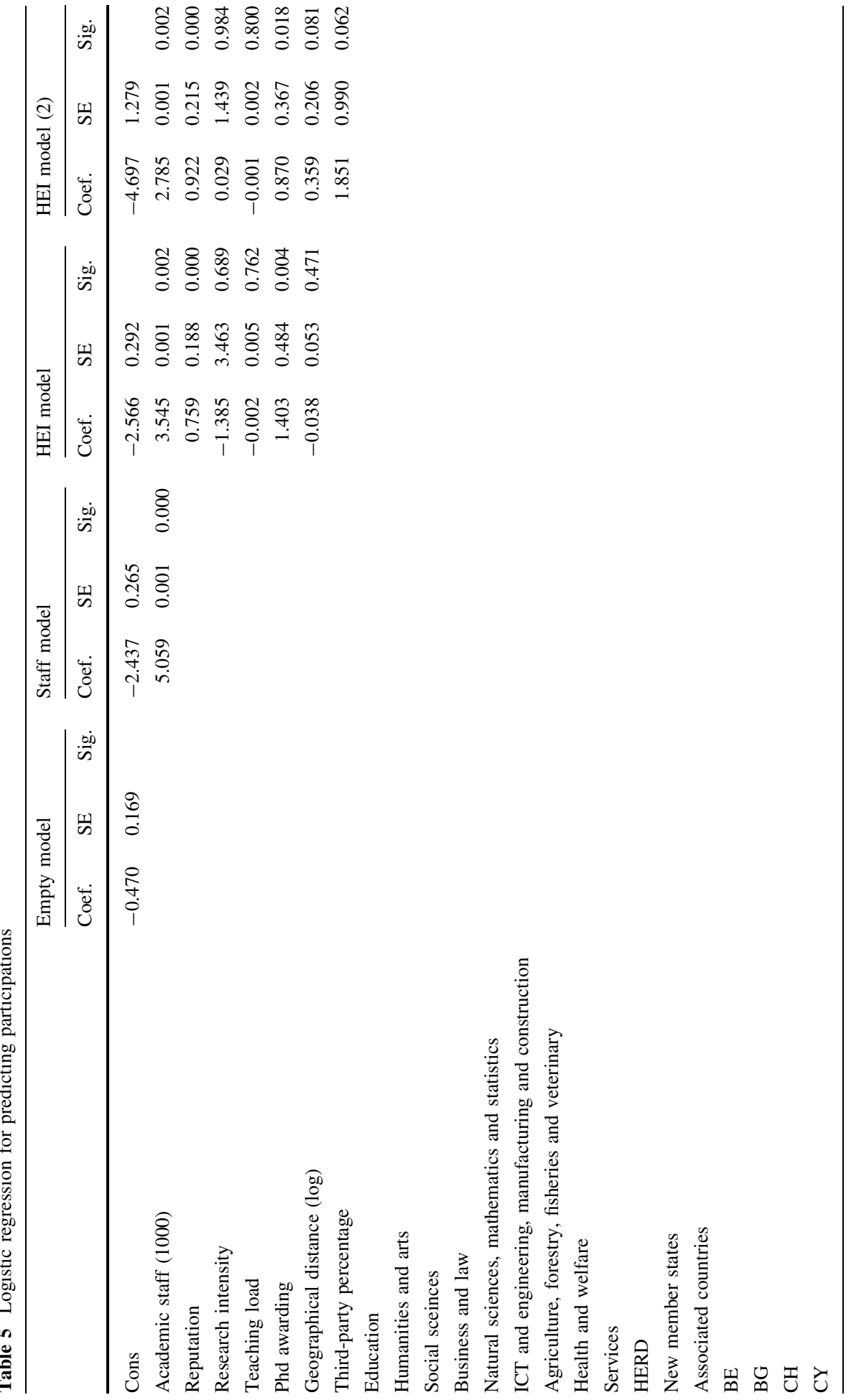




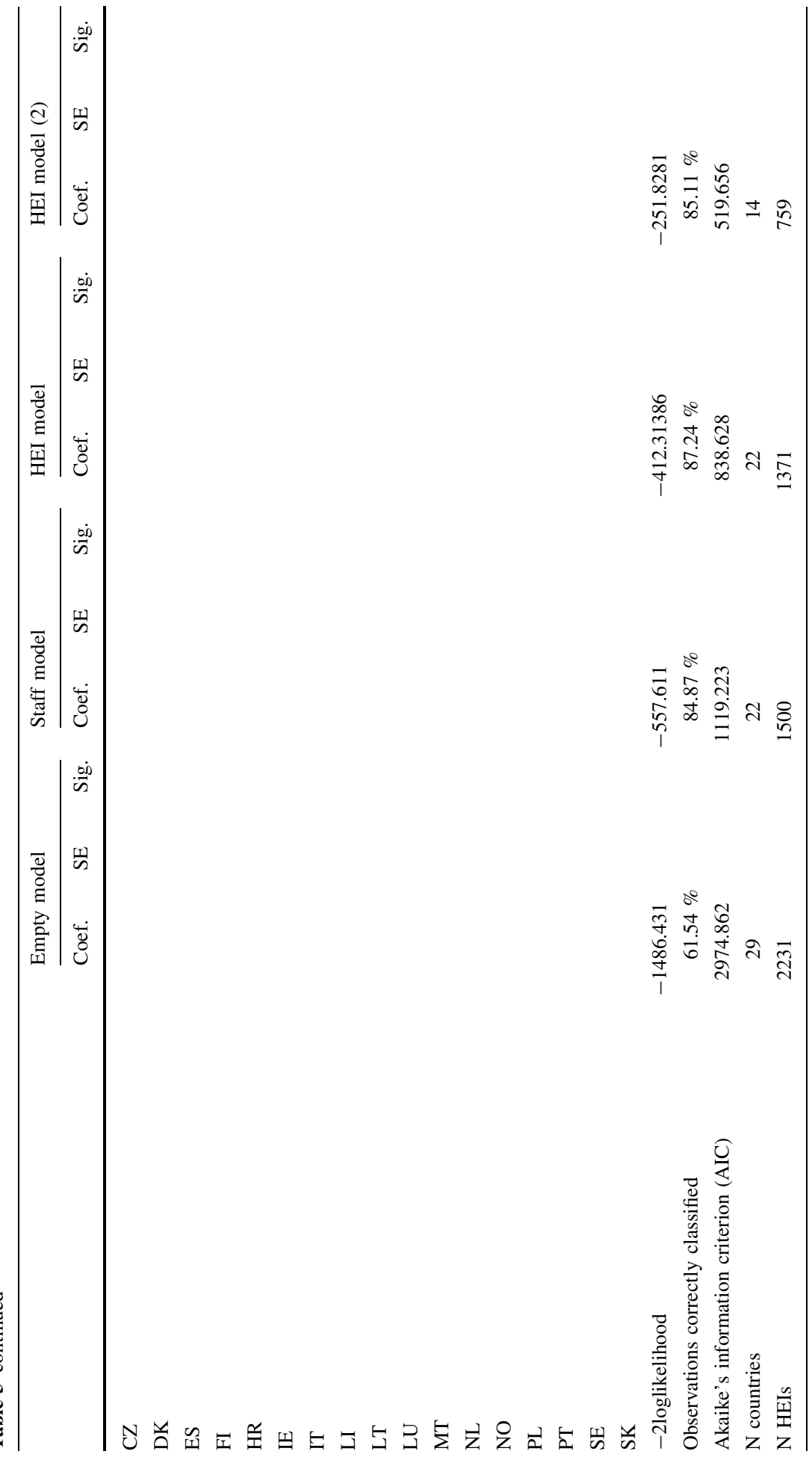




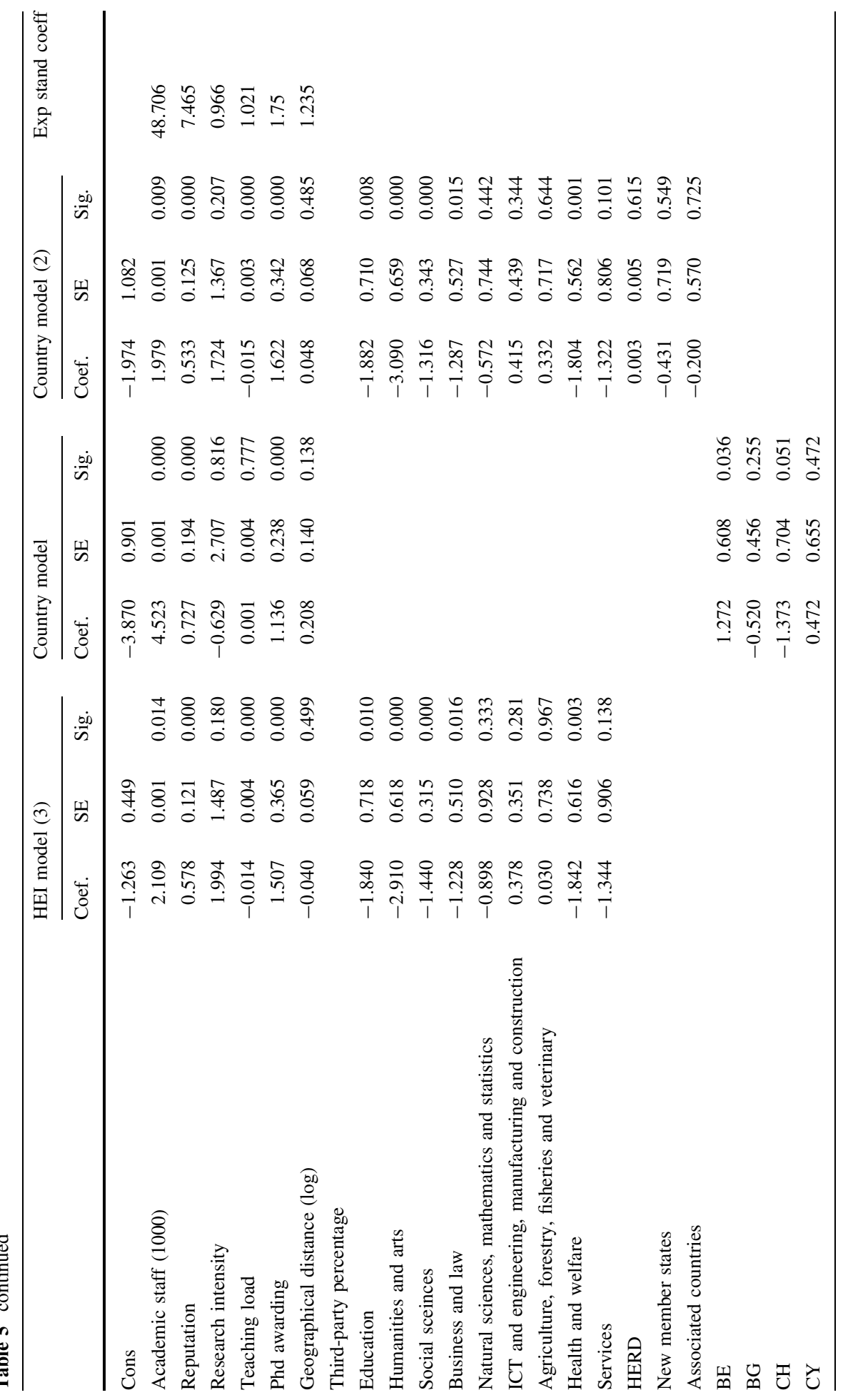




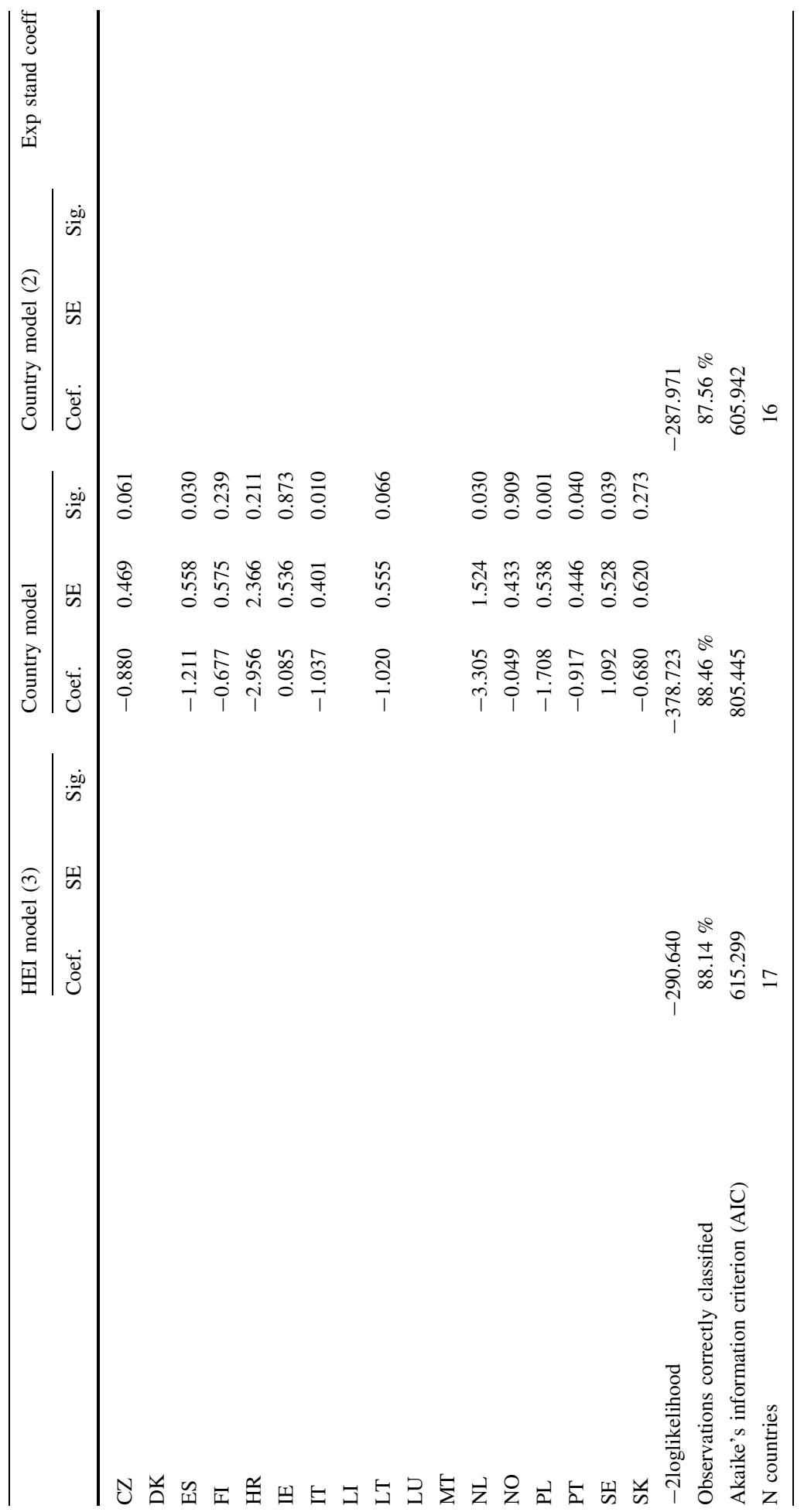




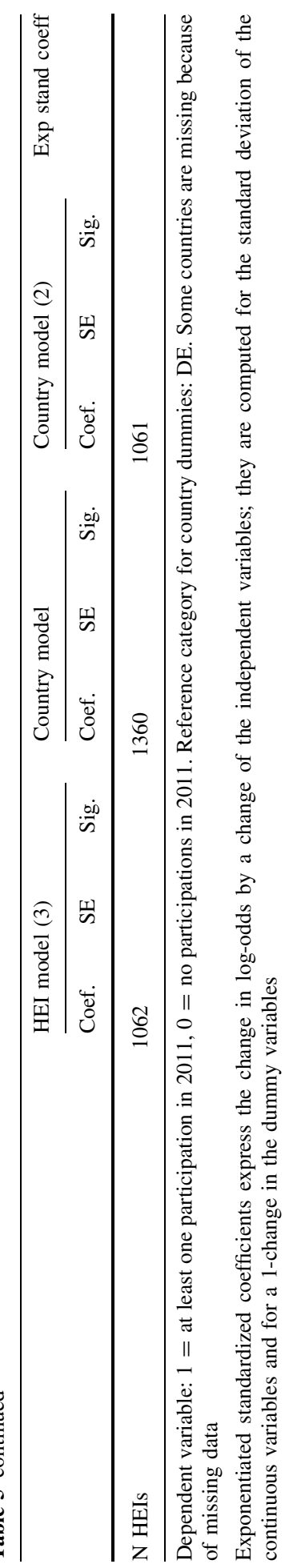


The performance of the model is remarkably good: in the HEI model with country dummies the percentage of correctly classified cases exceeds $75 \%$ in all countries and is between 85 and $90 \%$ for most of them.

Among the HEI characteristics, size has by far the strongest effect. Also the coefficients for the right to award a $\mathrm{PhD}$ and reputation are positive and significant in all models. On the contrary, research intensity is not significant, which can be explained by the fact that most of their effect is absorbed by the $\mathrm{PhD}$ awarding variable and by reputation. Teaching load is only significant and negative when the dummies for subject specialization are introduced, which is expected since there are systematic variations in the average number of students by staff per field, and therefore, this indicator is strongly influenced by the disciplinary composition.

The subject field dummies yield the expected results. HEIs specialized in humanities, education, social sciences, business and law, as well as health and services are less likely to participate in EU-FPs (the effect is particularly strong in the case of humanities). Finally, there is no evidence of a geographical effect, as coefficients of distance are never significant.

There is little evidence of country effects. The introduction of country dummies slightly improves the overall fit of the model, as shown by the AIC and by the percentage of correctly classified cases. Some of the country dummies are statistically significant and rather large, particularly for BE, CH, NL, PL and PT. At the same time, the coefficients of HEI characteristics are not significantly affected.

The significance of country coefficients should not be overstated as they are based on a small number of cases. An analysis of predictions shows that the model with country dummies reclassifies only 48 cases, i.e. about $3 \%$ of the sample and the model's fit is improved in a few individual countries (for Belgium 19 to 25 cases were correctly classified out of 27 cases, for the Netherlands 40-45 cases were correctly classified out of 50). Other country variables like HERD and the dummies for associated countries and New Member States are non-significant.

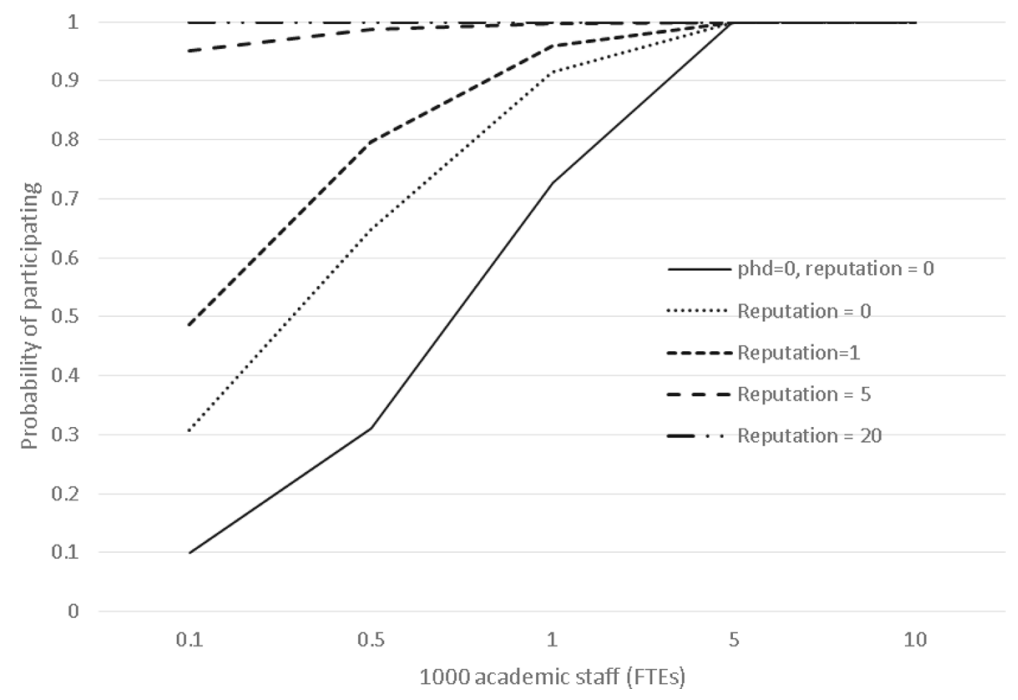

Fig. 2 Probability of participating as a function of HEI size, PhD awarding and reputation. Predicted probabilities by the HEI model 


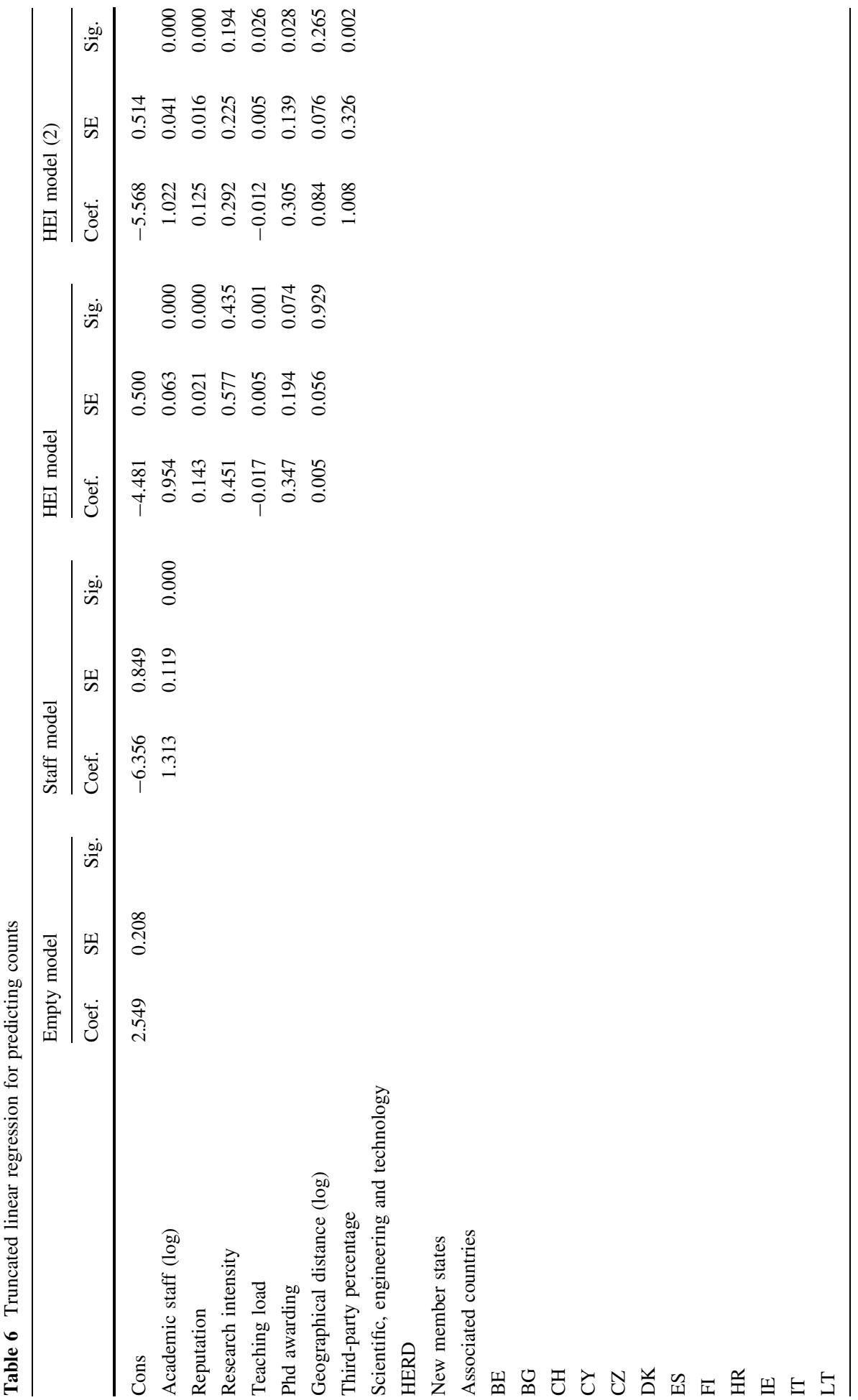




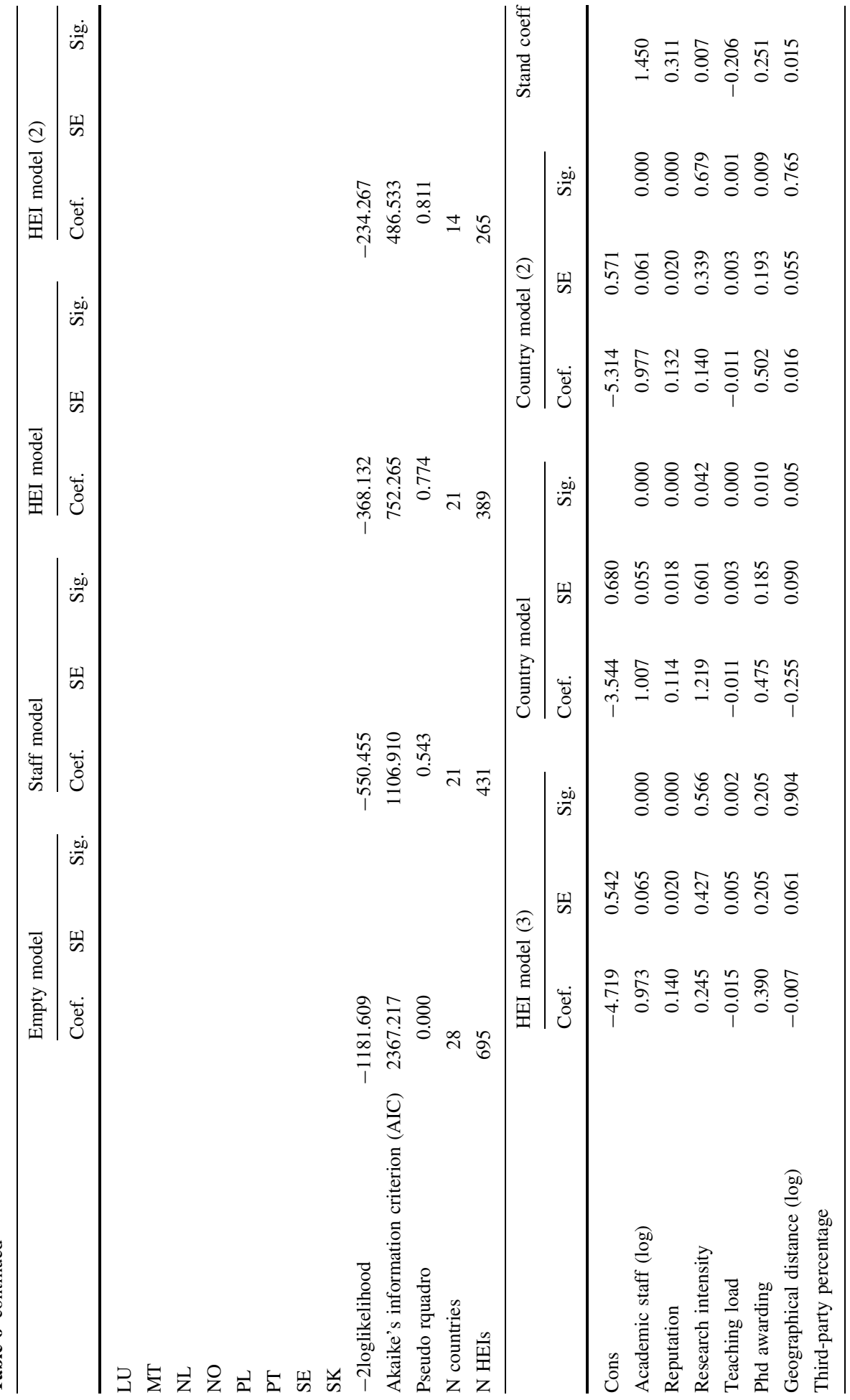




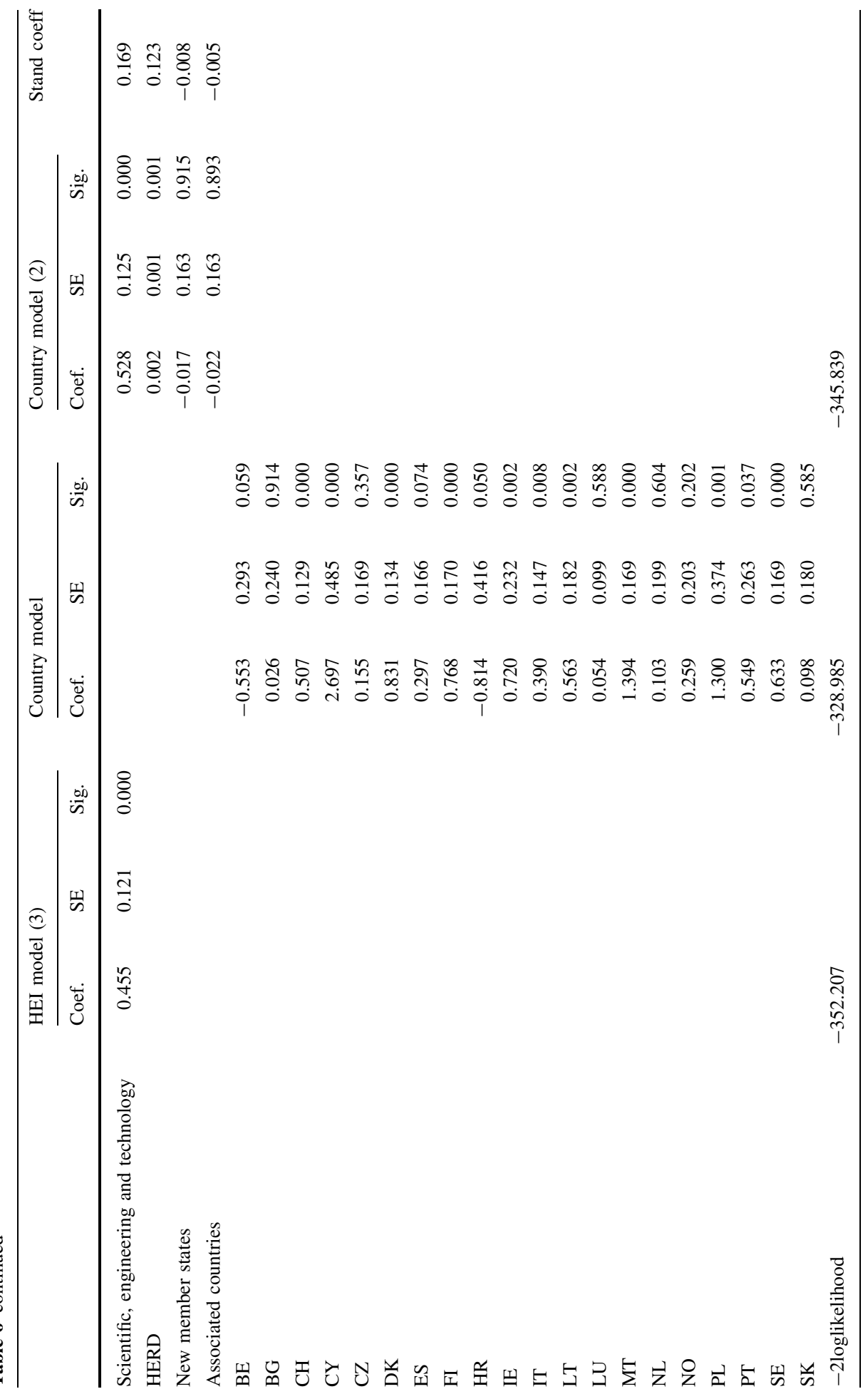




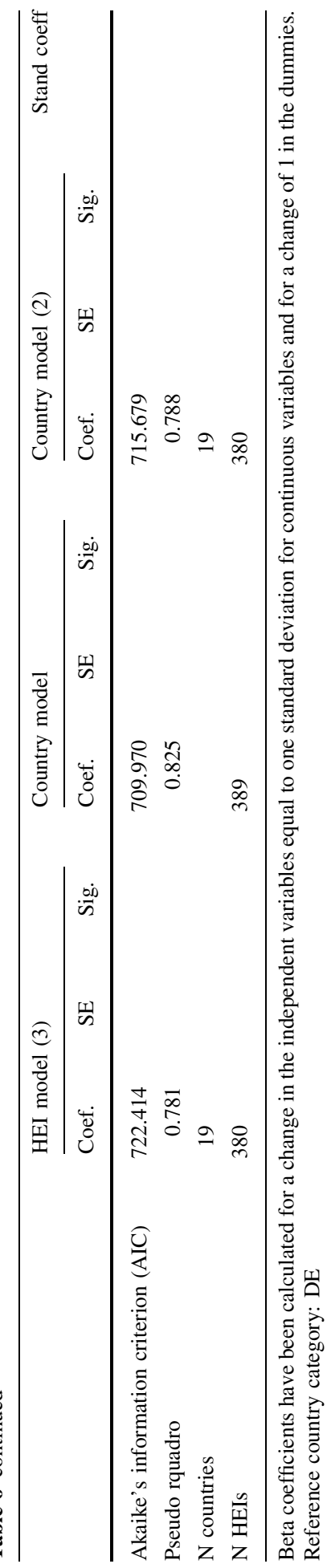


Figure 2 graphically displays the importance of the size effect, as compared with the $\mathrm{PhD}$ awarding dummy and to the level of reputation of the HEI. Non-PhD awarding HEIs, like Universities of Applied Sciences, have a fair probability of participating, but only if they are quite large - above 700 FTE of academic staff, which means in most cases more than 10,000 students. Universities with a lower reputation participate at an even smaller size, whereas the highly reputed HEIs participate even if they are extremely small. All large HEIs (above 1000 FTEs) participate independent of their reputation, but few nonresearch oriented HEIs reach this size.

\section{Factors associated with the number of participations}

Table 6 displays the results of a truncated linear regression using the ln of the number of participations as a dependent variable (limited to the HEIs with at least one project in 2011). We also apply a log transformation to the number of academic staff, while the other variables are not transformed since they are bounded. In terms of the models' fit, results are consistent with those on the probability of participating: academic staff showed the most improvement in the overall fit of the model, followed by the remaining HEI variables; additionally the introduction of country dummies slightly improves the fit, but does not affect the coefficients of the HEI variables.

Size and reputation are by far the most important organizational factors associated with EU-FP participation when we compare standardized coefficients. Once we introduce reputation, the coefficient of size is not statistically different from 1, implying that the number of participations is proportional to academic staff and thus that there are no direct scale effects of size. However, since size and reputation remain correlated (despite reputation being normalized by size), larger HEIs have more participations in EU-FP programs in respect to staff as an outcome of their higher reputation.

As for the other HEI characteristics, results are less clear: research intensity is significant only in the model with country dummies, which could be an outcome of systematic differences in this indicator by country due to the varying role of the $\mathrm{PhD}$ in national systems (Bonaccorsi et al. 2007); $\mathrm{PhD}$ awarding is only significant is some models and the importance of this variable is limited by the fact that the truncated sample is composed almost entirely by $\mathrm{PhD}$-awarding HEIs. Teaching load is negative and significant in all models, while the share of third-party funding is positive and significant. This might point to complementarities between national and European funding. However, the value of this finding is reduced by the small size of the sample and the fact that this share also includes European funding.

As expected, the impact of a stronger disciplinary orientation towards national sciences and engineering in EU-FP participations is positive and significant. Finally, there is no effect of geographical distance between HEIs headquarters and Brussels - the significant coefficient in the country dummies model is not really meaningful, since it refers to changes in the distance within countries. As in the logistic regression, evidence of country effects is slight. A number of country dummies are positive and significant, but it is difficult to find a clear pattern; in the last model, Higher Education R\&D expenditures are statistically significant as well, which would imply that countries invested more in higher education research have proportionally more participations.

Finally, Table 7 shows the results of a truncated linear regression for the number of participations in the year 2012, as an outcome of that number in 2008 and of organizational size and reputation in 2008. 
Results are consistent with the cross-sectional analysis. In the participation model, the coefficient of 2008 participations is not significantly different from 1, consistently with descriptive statistics showing a high stability of participation numbers. In the full model, the coefficient of 2008 participations is lower than 1, but reputation has a significant positive coefficient (while the one of 2008 size is not).

The interpretation is straightforward: current participations to EU-FP largely generate new ones, because they are borne from existing collaborative links, but there is some decay with time. At the same time, new participations are associated with HEI reputation and, therefore, highly-reputed HEIs move to the center of the EU-FP network until an equilibrium state is reached. In other words, reputational mechanisms maintain the stability of the network ensuring that consistently the higher reputed HEIs are found in its core and that, in the long term, an increase in reputation will also lead to larger number of EU-FP participations.

\section{Discussion and conclusions}

Our results confirm the hypothesis that the number of participations to EU-FP is strongly associated with organizational characteristics, particularly with HEI size and reputation. The importance of HEI characteristics was already recognized by previous works (Geuna 1998a), but for the first time we were able to show that they explain most of the difference in the number of participations. The predictive ability of the models is striking: about $88 \%$ of the HEIs are correctly classified between participating and non-participating, while about $80 \%$ of the variance in the number of participations is explained by the regression model.

This outcome was somewhat unexpected: given the importance of collaborative networks for EU-FP participations, one would have expected less influence of organizational characteristics and the importance of network effects, like the creation of closed groups of participants. Yet, this result is consistent with the well-known fact in social network analysis that, in many networks, the reputation of organizations plays a central role in determining the network structure and that network centrality is strongly associated with reputation (Borgatti and Everett 1999; Owen-Smith and Powell 2008).

The outcome of this process is a very strong and lasting concentration of EU-FP participations. A group of about 150 universities (out of $1000 \mathrm{PhD}$ awarding HEIs in our

Table 7 Truncated linear regression participations in 2012

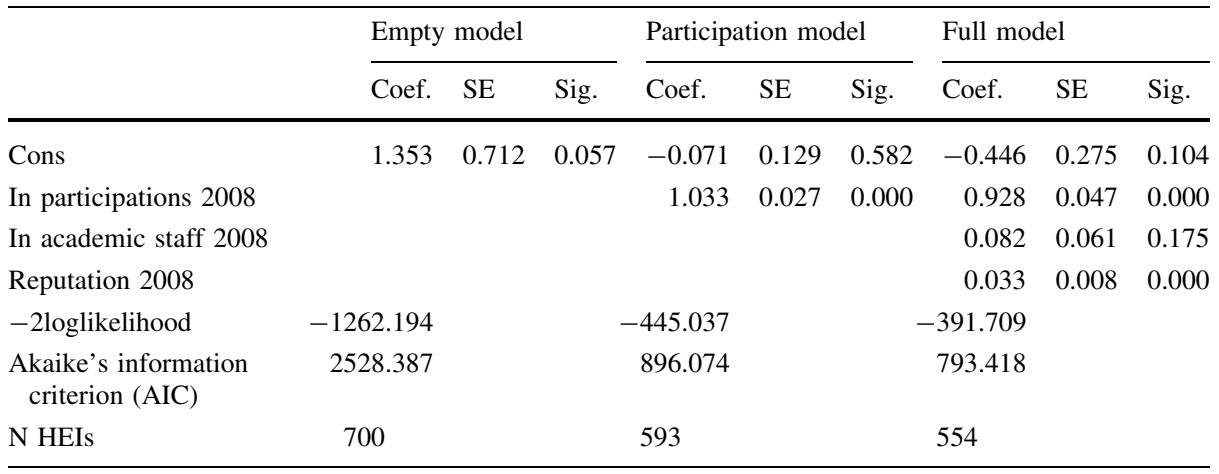


sample) accounted for over $70 \%$ of total participations in European projects in the year 2011 and EU-FP participations were even more concentrated than PhD students and scientific publications. This group is almost identical to the highly-reputed European universities - 148 of the 157 HEIs in our sample with more than 50 EU-FP participations are included in the Leiden ranking. The extent of participation in non-doctorate awarding HEIs, like Universities of Applied Sciences, remains very limited, as these account for more than half of the HEIs in our sample, but only $1 \%$ of the participations.

These results show how the collaborative nature of EU-FPs reinforces the role of organizational reputation in the acquisition of European funds. While the grant selection process is a rather uncertain process where quality is contested and there are wide variations in the extent reputation determines the selection outcome (Van den Besselaar and Leydesdorff 2009), the creation of network ties is more systematically associated with reputation, leading to a stronger association between reputation and acquisition of grants than for individual projects.

Further, there is only slight evidence of the presence of country effects and almost no evidence of the impact of the geographical distance from the European Commission on participations to EU-FPs. This applies particularly to the participation of New Member States, which is in line with the level that would be predicted from the characteristics of their HEIs. On the one hand, we might interpret this as a sign that European integration has gone so far that less central countries are no longer disadvantaged when participating in EU-FPs. On the other hand, systematic differences in the level of resourcing and reputation of HEIs translate into large differences in the levels of participations by country. This displays the double-edged nature of European integration, where diminishing barriers between countries go alongside with cumulative processes that reinforce a center and a periphery of European science.

In policy terms, the interpretation of these findings is somewhat ambiguous. They show how the will of promoting European research cooperation also led to the creation of a strong core of highly-reputed players, receiving a large share of European funding. This effect is largely due to social network effects and, therefore, it is likely to be present also in areas of EU-FPs where excellence is not solely the main selection criterion. This might interpreted as a positive sign that Europe is able to target excellence and concentrate resources to core universities, or it can be interpreted as a sign of conservatism in the allocation of resources, being largely driven by academic reputation. It would be interesting to repeat a similar analysis for different subprograms to investigate whether the strength of the effect differs by program area.

Similarly, the results concerning geography are also subject to discussion: they may be interpreted as a success in terms of creating a European Research Area, where competition takes place at the European level and national states have less influence on the allocation of (European) funds. At the same time, the emergence of a strong and closed core may occur at the expense of achieving cohesion and participation in the ERA from countries in eastern and southern Europe. This would raise the question of whether stronger cohesion policies, concerning specifically research, might be required.

Despite its value, our analysis has two limitations, which open important avenues for further research. First, the analysis is essentially cross-sectional: this is a suitable approach for our main goal, i.e. to analyze layering of the European higher education in terms of participations to EU-FPs and its association with organizational characteristics. There are theoretical reasons to expect stability of layering over time, as an outcome of the association between network structure and reputational structure and, indeed, this is shown by the literature (Paier and Scherngell 2011) and confirmed by our tests for the period 
2008-2012. However, some relevant questions can be answered only with longitudinal data. First, it would be important to investigate whether there is growing concentration of EU-FP participation over time, as foreseen by cumulative mechanisms, and whether this is associated with changes in the reputational hierarchy in European higher education. Second, issues of stability and time to equilibrium are relevant, i.e. how much time it requires to the EU-FP network to respond to changes in the reputational structure. Third, while our main focus was on stability of layering, a specific analysis of the cases of HEIs whose numbers of participations changed significantly over time would shed light on dynamic processes.

The second limitation is that we are not observing directly network processes and measuring network centrality and, therefore, the interpretation of our findings in terms of network structure can only be indirect. An analysis of EU-FP networks, including the organizational covariates, would assess more directly the generating mechanism of the association between organizational characteristics and number of participations. Such analysis would also allow analyzing the role of endogenous network effects, like social closure and reciprocity, once the role of organizational characteristics has been netted out, in determining the network structure. Given the endogeneity of network structure, suitable statistical models, like Exponential Random Graph Models, are required to this goal (Lusher et al. 2013).

Acknowledgments The authors acknowledge support from the European Union through the project Research infrastructures for the assessment of science, tecnology and innovation policy RISIS (Grant agreement no: 313082).

\section{References}

Annerberg, R., Begg, I., Acherson, H., Borrás, S., Hallen, A., Maimets, T., Mustonen, R., Raffler, H., Swings, J. \& Ylihonko, K. (2010). Interim Evaluation of the Seventh Framework Programme: Report of the Expert Group. European Commission.

Arnold, E. (2012). Understanding long-term impacts of R\&D funding: The EU Framework Programme. Research Evaluation, 21(5), 332-343.

Autant-Bernard, C., Billand, P., Frachisse, D., \& Massard, N. (2007). Social distance versus spatial distance in R\&D cooperation: Empirical evidence from European collaboration choices in micro and nanotechnologies*. Papers in Regional Science, 86(3), 495-519.

Banchoff, T. (2002). Institutions, inertia and European Union research policy. JCMS: Journal of Common Market Studies, 40(1), 1-21.

Barabasi, A. L., \& Albert, R. (1999). Emergence of scaling in random networks. Science (New York, N.Y.), 286(5439), 509-512.

Barajas and Huergo. (2010). International R\&D cooperation within the EU Framework Programme: Empirical evidence for Spanish firms. Economics of Innovation and New Technology, 19, 87-111.

Barber, M. J., Krueger, A., Krueger, T., \& Roediger-Schluga, T. (2006). Network of European Unionfunded collaborative research and development projects. Physical Review E, 73(3), 036132.

Bonaccorsi, A. (2014). Knoweldge, diversity and performance in european higher education. Edward Elgar: A Changing Landscape Cheltenam.

Bonaccorsi, A., Daraio, C., Lepori, B., \& Slipersaeter, S. (2007). Indicators on individual higher education institutions: Addressing data problems and comparability issues. Research Evaluation, 16(2), 66-78.

Bonaccorsi, A., Daraio, C., \& Simar, L. (2006). Advanced indicators of productivity of universities. An application of robust nonparametric methods to Italian data. Scientometrics, 66(2), 389-410.

Borgatti, S. P., \& Everett, M. G. (1999). Models of core/periphery structures. Social Networks, 21, 375-395.

Breschi, S., Cassi, L., Malerba, F., \& Vonortas, N. S. (2009). Networked research: European policy intervention in ICTs. Technology Analysis \& Strategic Management, 21(7), 833-857.

Breschi, S., \& Cusmano, L. (2004). Unveiling the texture of a European Research Area: Emergence of oligarchic networks under EU Framework Programmes. International Journal of Technology Management, 27(8), 747-772. 
Brinkman, P. T., \& Leslie, L. L. (1986). Economies of Scale in higher education: Sixty years of research. Review of Higher Education, 10(1), 1-28.

Burris, V. (2004). The academic caste system: Prestige hierarchies in $\mathrm{PhD}$ exchange networks. American Sociological Review, 69(2), 239-264.

Burt, R. S. (2005). Brokerage and closure: An introduction to social capital. Oxford: OUP.

Caloghirou, Y., Tsakanikas, A., \& Vonortas, N. S. (2001). University-industry cooperation in the context of the European Framework Programmes. The Journal of Technology Transfer, 26(1-2), 153-161.

Caloghirou, Y., Vonortas, N. S., \& Ioannides, S. (2002). Science and technology policies towards research joint ventures. Science and Public Policy, 29(2), 82-94.

Cameron, A. C., \& Trivedi, P. K. (1998). Regression analysis of count data. Econometric society monograph. Cambridge: Cambridge University Press.

Chessa, A., Morescalchi, A., Pammolli, F., Penner, O., Petersen, A. M. \& Riccaboni, M. (2013). Is Europe evolving toward an integrated research area? ArXiv Preprint arXiv:1302.3126.

Connolly, L. S. (1997). Does external funding of academic research crowd out institutional support? Journal of Public Economics, 64(3), 389-406.

Daraio, C., Bonaccorsi, A., Geuna, A., Lepori, B., et al. (2011). The European university landscape: a micro characterization based on evidence from the Aquameth project. Research Policy, 40(1), 148-164.

David, P. A., Hall, B. H., \& Toole, A. A. (2000). Is public R\&D a complement or substitute for private R\&D? A review of the econometric evidence. Research Policy, 29(4), 497-529.

Edler, J., Kuhlmann, S., \& Behrens, T. (2003). The changing governance of research and technology: The European research area. Cheltenam: Edward Elgar.

European Commission. (2011). Innovation union competitiveness report. Brussels: European Commission.

Evans, T. S., Lambiotte, R., \& Panzarasa, P. (2011). Community structure and patterns of scientific collaboration in business and management. Scientometrics, 89(1), 381-396.

Frenken, K., Hardeman, S., \& Hoekman, J. (2009). Spatial scientometrics: Towards a cumulative research program. Journal of Informetrics, 3(3), 222-232.

Geuna, A. (1996). The participation of higher education institutions in European Union Framework Programmes. Science and Public Policy, 23(5), 287-296.

Geuna, A. (1998a). Determinants of university participation in EU-funded R \& D cooperative projects. Research Policy, 26, 677-687.

Geuna, A. (1998b). Determinants of university participation in EU-funded R\&D cooperative projects. Research Policy, 26(6), 677-687.

Guzzetti, L. (1995). A brief history of European Union research policy. Brussels: European Commission.

Heller-Schuh, B., Barber, M., Henriques, L., Paier, M., Pontikakis, D., Scherngell, T., et al. (2011). Analysis of networks in European Framework Programmes (1984-2006). Luxembourg: Publications Office of the European Union.

Hoekman, J., Frenken, K., \& Tijssen, R. (2010). Research collaboration at distance: Changing spatial patterns of scientific collaboration in Europe. Research Policy, 39(5), 662-673.

Ijiri, Y., \& Simon, H. A. (1964). Business firm growth and size. The American Economic Review, 54(2), 77-89.

Kuhlmann, S. (2001). Future governance of innovation policy in Europe-Three scenarios. Research Policy, 30, 953-976.

Laudel, G. (2006a). The "quality myth": promoting and hindering conditions for acquiring research funds. Higher Education, 52, 375-403.

Laudel, G. (2006b). The art of getting funded: How scientists adapt to their funding conditions. Science and Public Policy, 33(7), 489-504.

Lepori, B., Barberio, V., Seeber, M., \& Aguillo, I. (2013). Core-periphery structures in national higher education systems. A cross-country analysis using interlinking data. Journal of Infometrics, 7(3), $622-634$.

Lepori, B., \& Kyvik, S. (2010). The research mission of universities of applied science and the future configuration of higher education systems in Europe. Higher Education Policy, 23, 295-316.

Lepori, B., Probst, C., \& Baschung, L. (2010). Patterns of subject mix of higher education institutions: A first empirical analysis from the AQUAMETH database. Minerva, 48(1), 73-99.

Long, J. S. (1997). Regression models for categorical and limited dependent variables. Thousand Oaks: Sage.

Lusher, D., Koskinen, J. \& Robins, G. (2013). Exponential random graph models for social networks: Theories, methods and applications. Cambridge, MA: Cambridge University Press.

Luukkonen, T. (2000). Additionality of EU framework programmes. Research Policy, 29, 711-724.

Luukkonen, T., \& Nedeva, M. (2010). Towards understanding integration in research and research policy. Research Policy, 39(5), 674-686. 
Malerba, F., Vonortas, N., Breschi, S., \& Cassi, L. (2006). Evaluation of progress towards a European Research Area for information society technologies. Report to European Commission, DG Information Society and Media.

Nedeva, M. (2012). Between the global and the national: Organising European science. Research Policy, 42(1), 220-230.

Nokkala, T., Heller-Schuh, B., \& Paier, M. (2011). Ranking lists and European framework programmes: Does university status matter for performance in framework programmes? In P. N. Teixeira \& D. D. Dill (Eds.), Public vices, private virtues? Assessing the effects of marketization in higher education (pp. 111-140). Rotterdam: Sense Publishers.

Ormala, E., \& Vonortas, N. S. (2005). Evaluating the European Union's Research Framework Programmes: 1999-2003. Science and Public Policy, 32(5), 399-406.

Owen-Smith, J., \& Powell, W. W. (2008). Networks and institutions. In R. Greenwood, C. Oliver, K. Shalin, \& R. Suddaby (Eds.), The SAGE handbook of organizational institutionalism (pp. 594-621). London: Sage.

Paier, M., \& Scherngell, T. (2011). Determinants of collaboration in European R\&D networks: Empirical evidence from a discrete choice model. Industry and Innovation, 18(1), 89-104.

Rivera, M. T., Soderstrom, S. B., \& Uzzi, B. (2010). Dynamics of dyads in social networks: Assortative, relational, and proximity mechanisms. Annual Review of Sociology, 36, 91-115.

Roediger-Schluga, T., \& Barber, M. J. (2008a). R\&D collaboration networks in the European Framework Programmes: Data processing, network construction and selected results. International Journal of Foresight and Innovation Policy, 4(3), 321-347.

Roediger-Schluga, T., \& Barber, M. (2008b). R\&D collaboration networks in the European Framework Programmes: data processing, network construction and selected results. International Journal of Foreseight and Innovation Policy, 4(3-4), 321-347.

Scherngell, T., \& Barber, M. (2011). Distinct spatial characteristics of industrial and public research collaborations: evidence from the fifth EU Framework Programme. The Annals of Regional Science, 46(2), 247-266.

Scherngell, T., \& Lata, R. (2013). Towards an integrated European Research Area? Findings from Eigenvector spatially filtered spatial interaction models using European Framework Programme data*. Papers in Regional Science, 92(3), 555-577.

Snijders, T., \& Bosker, R. (2004). Multilvel analysis. London: SAGE.

UOE. (2013). UOE data collection on education systems volume 1. Manual concepts, definitions, classifications. Montreal: UNESCO.

Van den Besselaar, P., \& Leydesdorff, L. (2009). Past performance, peer review and project selection: a case study in the social and behaviouraval sciences. Research Evaluation, 18(4), 273-288.

Van Raan, A. F. J. (2008). Bibliometric statistical properties of the 100 largest European universities: Prevalent scaling rules in the science system. Journal of the American Society for Information Science and Technology, 59(3), 461-475.

Veugelers, R., \& Cassiman, B. (2005). R\&D cooperation between firms and universities. Some empirical evidence from Belgian manufacturing. International Journal of Industrial Organization, 23(5), 355-379.

Viner, N., Green, R., \& Powell, P. (2006). Segmenting academics: Resource targeting of research grants. Science and Public Policy, 33(3), 166-178.

Viner, N., Powell, P., \& Green, R. (2004). Institutionalized biases in the award of research grants: A preliminary analysis revisiting the principle of accumulative advantage. Research Policy, 33, 443-454. 